\title{
Combined transmission electron microscopy and x-ray study of the microstructure and texture in sputtered Mo films
}

\author{
O. P. Karpenko, J. C. Bilello, and S. M. Yalisove \\ Department of Materials Science and Engineering, University of Michigan, 2300 Hayward Street, \\ Ann Arbor, Michigan 48109-2136
}

(Received 4 May 1994; accepted for publication 7 July 1994)

\begin{abstract}
The microstructure and texture of thin Mo films sputtered onto the native oxide of $\mathrm{Si}(100)$ wafers were investigated with both conventional refiection $x$-ray pole figures, and transmission electron microscopy and diffraction. Films were grown at two deposition rates (powers), $34 \mathrm{~nm} / \mathrm{min}(1.5$ $\mathrm{kW})$ and $67 \mathrm{~nm} / \mathrm{min}(3.9 \mathrm{~kW})$, onto both moving and stationary substrates, under otherwise identical experimental conditions. The microstructure of the Mo films evolved into a zone 2 microstructure within the first $2 \mu \mathrm{m}$ of growth. The development of both out-of-plane and in-plane textures was found to be influenced by deposition rate and geometry. Films grown at the lower deposition rate exhibited predominantly $\{110\}$ textures, while films grown at the higher rate exhibited predominantly $\{110\}$ textures up to a film thickness of $\sim 0.5 \mu \mathrm{m}$ and $\{111\}$ textures above a film thickness of $\sim 1 \mu \mathrm{m}$. Films with the $\{110\}$ textures developed grains with elongated footprints and faceted surfaces, while films with the $\{111\}$ textures developed grains with elongated triangular footprints and faceted surfaces. In all of the films deposited onto moving substrates, an alignment of the grains normal to the tangent plane (defined by the substrate normal and the direction of platen rotation) was observed. In all of the films deposited onto stationary substrates, the development of an in-plane texture was suppressed. These results suggest that a combination of geometric, energetic, and kinetic mechanisms are contributing to the evolution of the microstructure and texture in the Mo films.
\end{abstract}

\section{INTRODUCTION}

Thin metal films play an important role in many technological applications such as ultralarge scale integrated electronic circuits, ${ }^{1}$ protective coatings, ${ }^{2}$ and magnetic recording media and devices. ${ }^{3-6}$ All of these technologies depend critically on the development of specific properties in the films for optimal performance. Since the relevant physical properties of a film are often determined by its microstructure, a great deal of effort has been devoted to studying the growth of thin metal films. Many studies have described the microstructure of films grown by physical vapor deposition at lower temperatures as being polycrystalline and columnar in nature. In addition, the development of these microstructures has been modeled in terms of atomistic mechanisms which operate during deposition. Typically, these models use a zone scheme which classifies polycrystalline thin film microstructures into four categories (zones) based on particular microstructural features. ${ }^{7-10}$ Both experimental and theoretical studies have also addressed the influence of many deposition parameters (incidence angle of the flux, ${ }^{9,11}$ flux energy, ${ }^{12,13}$ substrate temperature, ${ }^{7,8}$ type of sputtering gas, ${ }^{13}$ sputtering gas pressure, ${ }^{8,12,13}$ and the presence of impurities ${ }^{14}$ ) on the development of the thin film microstructures and thin film properties.

The final properties of a thin film are also strongly dependent on the texture, or net crystallographic orientation of grains within a film..$^{3,15-17}$ Because of the anisotropic nature of most materials, thin film properties and performance will be dramatically affected by changing the crystallographic orientation of the grains within a film both in the direction of growth (out-of-plane texture) and in the plane of growth (in- plane texture). For example, the type and degree of texture in thin films has been found to significantly affect the mean time to failure of $\mathrm{Al}$ metallizations, ${ }^{15,16}$ as well as the magnetic anisotropy in many magnetic thin film systems. ${ }^{3-5}$ The development of preferred crystallographic orientations in thin films grown onto single crystal substrates has been studied in great detail and has been found to depend on several factors including differences in the structure and the free energies between the film and the substrate, ${ }^{20,21}$ surface roughness, ${ }^{22}$ and lattice reconstructions. However, in many technologically important applications thin films are deposited onto amorphous substrates where substrate/film interactions are less dominant. In such cases, the resulting films tend to be polycrystalline with varying degrees of out-ofplane and in-plane texture. Currently, the development of texture in these polycrystalline films is not well understood and appears to be a complex process which depends on the interplay of many kinetic and energetic factors. ${ }^{23-31}$ Due to this limited understanding, the investigation of the evolution of texture in polycrystalline thin metal films, deposited onto amorphous substrates, warrants more attention.

One technologically important class of materials which merits further investigation is refractory metals. Because of their many favorable materials properties, refractory metals such as Mo are being used in a large number of thin film applications. ${ }^{2,32,33}$ For example, high strength and melting temperature make Mo an ideal candidate for use in high temperature strengthened multilayer films. ${ }^{2}$ In addition, high optical absorbency allows Mo to be used as a component in the fabrication of soft $x$-ray mirrors for use in applications such as extreme ultraviolet lithography. ${ }^{32}$ This study focuses on identifying the development of both out-of-plane and in- 

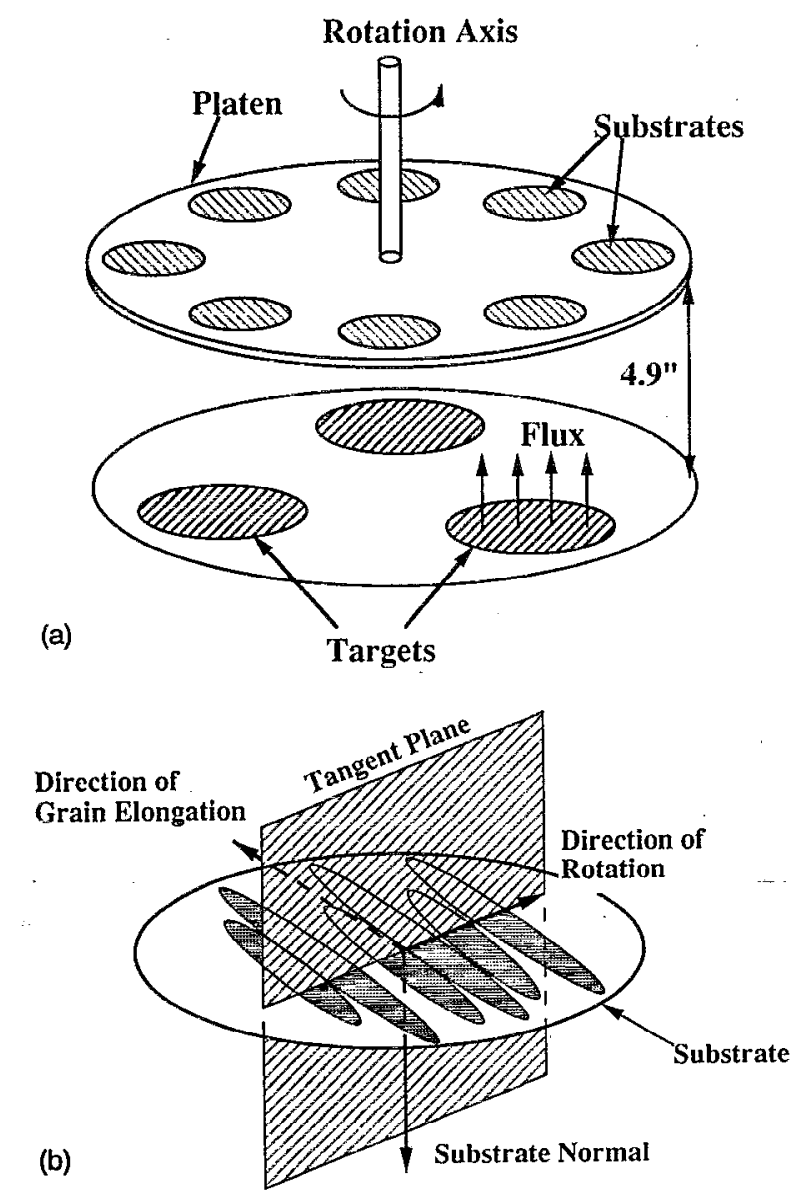

FIG. 1. (a) Geometry of the sputtering system. (b) Definition of the tangent plane: the relationship between the direction of rotation, the substrate normal and the direction of grain elongation.

plane texture in and the microstructure of thin Mo films sputter deposited onto the native oxide of $\mathrm{Si}(100)$ wafers.

\section{EXPERIMENT}

Mo films of various thicknesses were grown in a cryopumped sputter deposition system with a base pressure of $5.0 \times 10^{-6}$ Torr and a sputter-up geometry [see Figs. 1(a), 1(b)]. As-received $\mathrm{Si}(100)$ wafers were used as substrates and were mounted on a rotatable platen, $4.9 \mathrm{in}$. above the sputtering target. Prior to deposition, the Mo target was presputtered for $3 \mathrm{~min}$ in order to remove surface oxides and reduce impurity incorporation into the film: Films were then sputter deposited onto the native oxide of the $\mathrm{Si}$ wafers from 6 in. dc planar magnetron sources at two deposition rates (powers), $34 \mathrm{~nm} / \mathrm{min}(1.5 \mathrm{~kW})$ and $67 \mathrm{~nm} / \mathrm{min}(3.9 \mathrm{~kW})$, using argon at a constant pressure of $10 \mathrm{mTorr}$. During deposition the platen was either spun at $20 \mathrm{rpm}$ (dynamic deposition geometry), or held in a fixed position with the substrate directly above the sputtering target (static deposition geometry). Substrates were not intentionally heated, and their temperatures did not exceed $\sim 300^{\circ} \mathrm{C}\left(\sim 0.19 T_{m}\right)$ during deposition.

Thin film texture was measured from reflection $x$-ray pole figures collected using a Rigaku Rotaflex x-ray system equipped with a $12 \mathrm{~kW}$ rotating anode x-ray source $(\mathrm{Cu} \mathrm{K \alpha}$

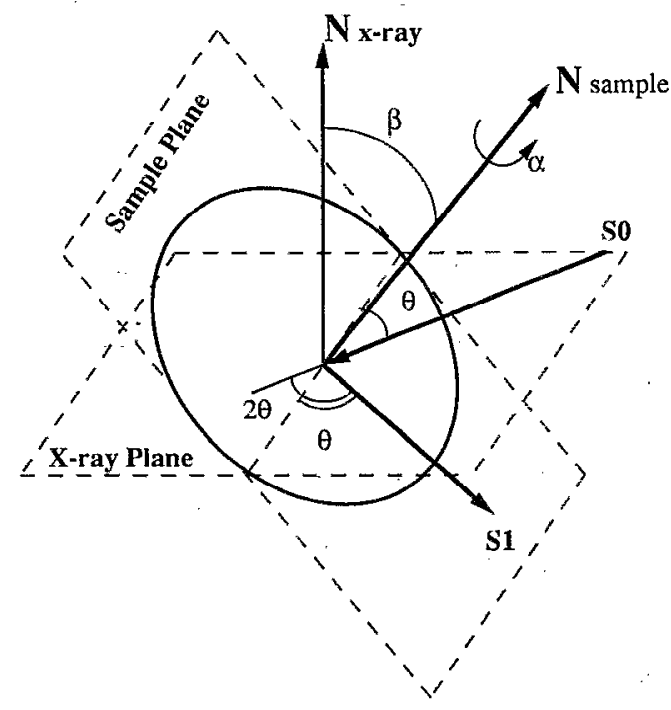

FIG. 2. Schultz geometry for reflection $\mathrm{x}$-ray pole figures.

radiation) and a Rigaku texture diffractometer configured in the Schultz geometry (see Fig. 2). ${ }^{34}$ Pole figures for (110), (200), and (211) poles were collected for all of the Mo thin films, as well as for a random polycrystalline Mo standard. The Mo standard, prepared by powder pressing and sintering, had an average grain size $>10 \mu \mathrm{m}$ and was thick enough to absorb $\approx 100 \%$ of the incident $x$ rays.

In order to simplify the interpretation of the pole figures, the diffraction intensities in the pole figures for the Mo thin films were normalized to the diffraction intensities in the pole figures for the Mo standard. The normalization procedure for a Mo (110) pole figure is summarized in Eq. (1) and below

$$
I_{\mathrm{norm}}(\alpha, \beta)=\left[I_{0}(a, \beta)-I_{\mathrm{bkg}}(\alpha, \beta)\right]^{*} A(\beta, \theta) / I_{\mathrm{std}}(\alpha, \beta),
$$

$I_{\text {norm }}(\alpha, \beta)=$ normalized diffraction intensity in the

(110) pole figure,

$I_{0}(\alpha, \beta)=$ diffraction intensity for the Mo film

in the (110) pole figure,

$I_{\mathrm{hkg}}(\alpha, \beta)=$ background diffraction intensity

for the Mo film,

$I_{\text {std }}(\alpha, \beta)=$ diffraction intensity for the Mo standard

in the (110) pole figure,

$$
\begin{gathered}
A(\beta, \theta)=[1-\operatorname{cxp}(-2 \mu T / \sin \theta \sin \beta)] / \\
{[1-\exp (-2 \mu T / \sin \theta)] .{ }^{35}}
\end{gathered}
$$

The $\mathrm{x}$-ray absorption correction terms $\beta$ and $\theta$ are defined in Fig. 2. 
In addition to the $(110)\left(2 \theta \approx 40.5^{\circ}\right),(200)\left(2 \theta \approx 58.6^{\circ}\right)$, and (211) $\left(2 \theta \approx 73.7^{\circ}\right)$ pole figures for the Mo films and the Mo standard, background pole figures were collected at a diffraction condition not satisfying any of the Bragg conditions for Mo $\left(2 \theta=50.0^{\circ}\right)$. The diffraction intensities in the background pole figure were subtracted from the diffraction intensities in the Mo (110) thin film pole figure in order to minimize contributions from air scattering and systematic noise. Next, the background subtracted diffraction intensities were corrected for changes in $x$-ray absorption through the thickness of the film. The changes in $x$-ray absorption were a result of changes in the angle, $\beta$, between the sample normal and the scattering vector. Finally, the corrected diffraction intensities in the Mo thin film (110) pole figure were divided by the diffraction intensities in the Mo standard (110) pole figure.

The strength of the texture in each film, as compared to the strength of the texture in the randomly oriented Mo standard, was also quantified. This procedure involved correcting the diffraction intensities in the normalized pole figures for differences in the diffracting volume between the Mo film and the Mo standard. Values obtained in this manner represented a "times random" measure of texture in each film. ${ }^{36} \mathrm{It}$ is noted that exact values for the degree of texture in a film were difficult to calculate since the diffracting volumes for the Mo films and the Mo standard were not well known.

Reflection $x$-ray pole figures were useful in providing information about the type and degree of texture in the Mo films, but were limited in several respects. The interpretation of pole figures collected from very thin films $(t<800 \AA)$ was difficult because of low count rates resulting from the small diffracting volume of the samples, and because of contributions to the scattering from the substrate. In addition, since the reflection $x$-ray pole figures relied on a symmetric $\theta-2 \theta$ geometry and the incident $\mathrm{x}$ rays were highly penetrating $\left(I_{0}\right.$ drops by a factor of $1 / e$ at a thickness of $\approx 6 \mu \mathrm{m}$ in Mo for $\mathrm{Cu} K \alpha$ radiation), the resulting diffracted signal represented an average film texture of the top $\approx 2 \mu \mathrm{m}$ of the film. This averaging effect also made it difficult to identify all of the texture components in a film, particularly when a specific component represented only a small volume fraction of the entire film $(<5 \%)$. In addition, practical geometric considerations in sample manipulation limited the range of angles accessible to the reflection pole figures $\left(\beta=90^{\circ}-15^{\circ}\right)$ and did not allow the collection of diffraction information from planes normal to the direction of growth.

Complementary structural information was obtained from both plan view and cross section transmission electron diffraction (TED) and microscopy (TEM). Plan-view TEM samples were prepared by ultrasonic cutting, mechanical back-thinning to $\sim 125 \mu \mathrm{m}$ and chemical etching to perforation using a $\mathrm{HNO}_{3}: \mathrm{HF}: \mathrm{CH}_{3} \mathrm{COOH}$ mixture (3:5:3). Additional ion milling $\left(\mathrm{Ar}^{+}\right.$ions at $\left.5 \mathrm{keV}\right)$ was performed when necessary to produce electron transparent regions in the specimens. Since the sample preparation involved thinning from the back side, electron transparent regions were produced near the top $\sim 500 \AA$ of the film without altering the surface structure of the film. Cross-section TEM samples were prepared by substrate cleavage, mechanical thinning to

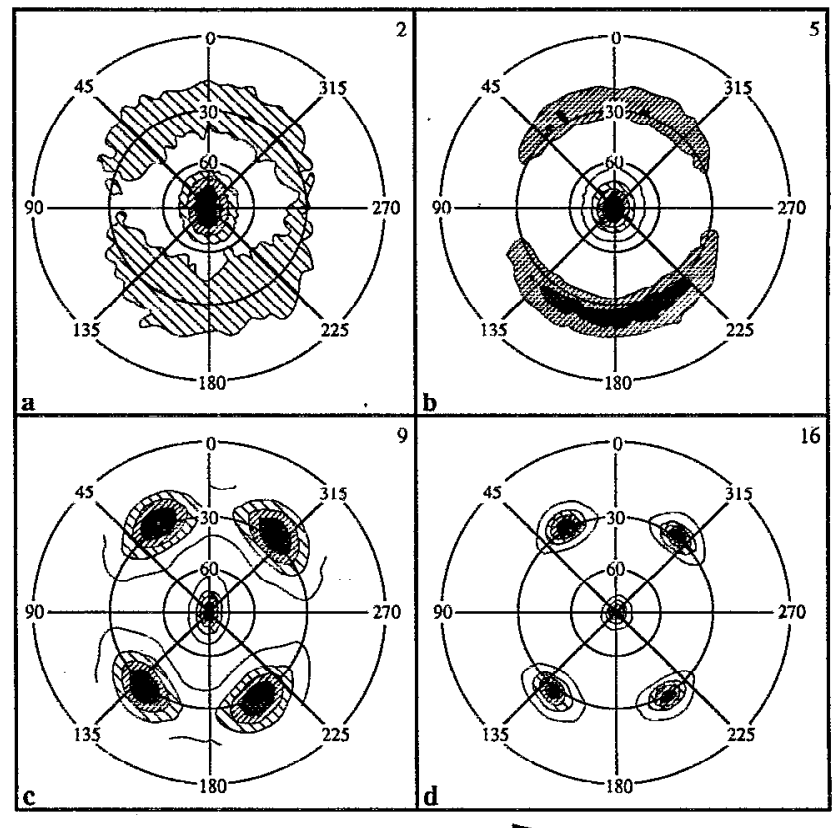

Direction of Rotation

Relative Intensity: $\square 90 \%, \quad 70 \%$, , $50 \%, \triangle 30 \%, \square 10 \%$

FIG. 3. (110) pole figures for Mo films deposited at $34 \mathrm{~nm} / \mathrm{min}$ in the dynamic deposition geometry. Note: In all of the pole figures the sample normal is parallel to the page normal. The maximum "times random" value for diffraction intensity in each pole figure is indicated in the upper righthand corner of each figure. Relative intensity refers to the percentage of the maximum "times random" diffraction intensity in each pole figure. These measurements indicate that $\sim 80 \%-85 \%$ of the grains in each film are oriented so that their (110) poles lie within the angular spread defined by the regions with $>50 \%$ relative intensity: (a) $200 \mathrm{~nm}$ Mo film deposited at 34 $\mathrm{nm} / \mathrm{min}$, (b) $500 \mathrm{~nm}$ Mo film deposited at $34 \mathrm{~nm} / \mathrm{min}$, (c) $1 \mu \mathrm{m}$ Mo film deposited at $34 \mathrm{~nm} / \mathrm{min}$, (d) $2 \mu \mathrm{m}$ Mo film deposited at $34 \mathrm{~nm} / \mathrm{min}$.

$\sim 50 \mu \mathrm{m}$, polishing, and ion milling to perforation $\left(\mathrm{Ar}^{+}\right.$ions at $5 \mathrm{keV}$ ). TEM analysis was performed using a Philips 420 $\mathrm{T}$ electron microscope, operating at $120 \mathrm{kV}$, and a JEOL $4000 \mathrm{EX}$ electron microscope, operating at $400 \mathrm{kV}$.

\section{RESULTS}

\section{A. Dynamic deposition geometry}

The development of out-of-plane texture and in-plane texture in Mo films sputtered onto moving substrates was studied as a function of film thickness and deposition rate with reflection $\mathrm{X}$-ray pole figures and TEM. $\mathrm{X}$-ray pole figure analysis of the films showed no evidence of either out-ofplane or in-plane texture in any films for layers thinner than $80 \mathrm{~nm}$. A weak $\{110\}$ out-of-plane texture was seen in the (110) pole figures for $80 \mathrm{~nm}$ films, grown at the lower deposition rate. At a film thickness of $200 \mathrm{~nm}$, a strong $\{110\}$ out-of-plane texture had developed in the films deposited at the lower rate [Fig. 3(a)], and a slightly weaker $\{110\}$ out-ofplane texture had developed for the films deposited at the higher rate [Fig. 4(a)]. For these films, no in-plane texture was detected, as near-complete axial symmetry of the diffraction intensity about the substrate normal was observed in the pole figures. The intensity of the $\{110\}$ out-of-plane tex- 


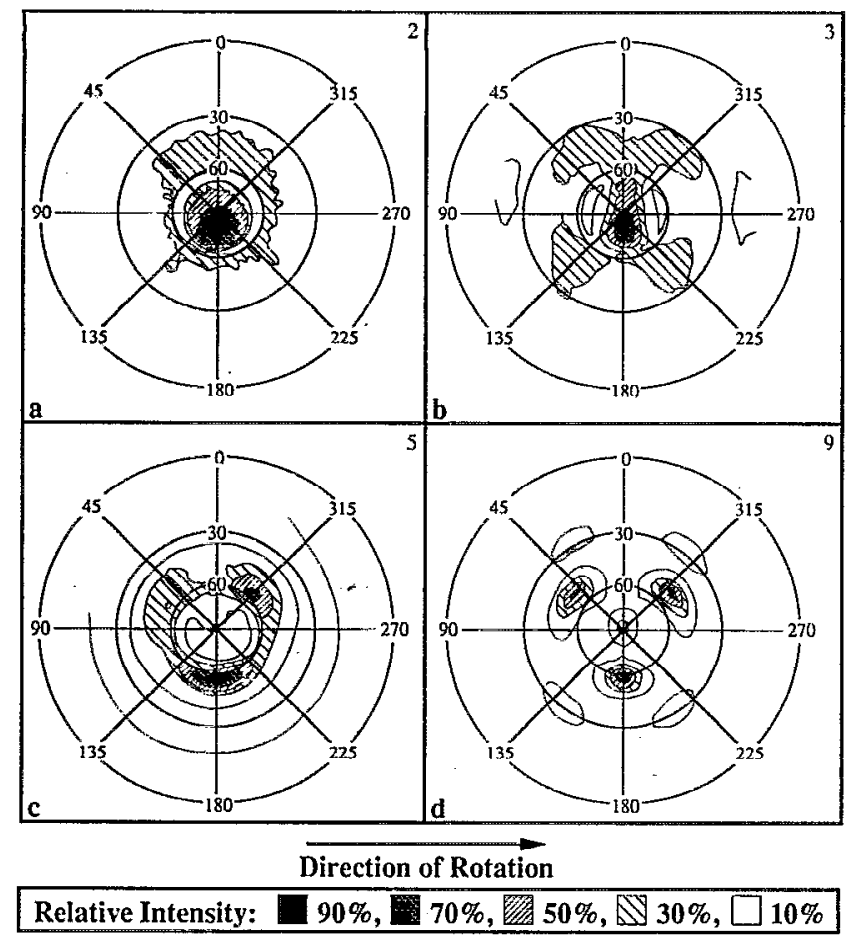

FIG. 4. (110) pole figures for Mo films deposited at $67 \mathrm{~nm} / \mathrm{min}$ in the dynamic deposition geometry. See note in Fig. 3 caption: (a) $200 \mathrm{~nm}$ Mo film deposited at $67 \mathrm{~nm} / \mathrm{min}$, (b) $500 \mathrm{~nm}$ Mo film deposited at $67 \mathrm{~nm} / \mathrm{min}$, (c) $1 \mu \mathrm{m}$ Mo film deposited at $67 \mathrm{~nm} / \mathrm{min}$, (d) $2 \mu \mathrm{m}$ Mo film deposited at 67 $\mathrm{nm} / \mathrm{min}$.

ture, as seen in the pole figures, continued to increase with film thickness for films deposited at $34 \mathrm{~nm} / \mathrm{min}$. However, the intensity of the $\{110\}$ out-of-plane texture increased at a slower rate for films deposited at $67 \mathrm{~nm} / \mathrm{min}$.

The presence of significant in-plane texture was detected in the sputtered Mo films at and above a film thickness of $500 \mathrm{~nm}$ [Figs. 3(b), 4(b)]. Both Figs. 3(b) and 4(b) show a discontinuous, anisotropic distribution of the diffraction intensity about the substrate normal and suggest a $\{110\}$ inplane texture. This anisotropy became more pronounced as the film thickness was increased. By a thickness of $1 \mu \mathrm{m}$, $\{110\}$ [Fig. 3(c)] and $\{111\}$ [Fig. 4(c)] in-plane textures could be distinguished in the pole figures for all films. The distribution of poles in the $\{110\}$ and $\{111\}$ textured films matched the distribution of poles in standard cubic (110) and (111) stereographic projections. In addition, the angular spread of the diffraction maxima [i.e., full width at half maximum (FWHM) of the diffraction peaks] decreased with increasing film thickness [Figs. 3(d), 4(d)]. This decreased FWHM implies a better alignment of the grains in the plane of growth. In all of the films with a $\{110\}$ in-plane texture, pole figures suggested an alignment of a Mo $\langle 100\rangle$ direction normal to the tangent plane [the plane defined by the substrate normal and the direction of platen rotation, as seen in Fig. 1(b)]. Similarly, films with a $\{111\}$ in-plane texture exhibited an alignment of a Mó. $\langle 112\rangle$ direction normal to the tangent plane.

The results of the $\mathrm{x}$-ray study were corroborated by the results of a TEM and TED microstructural analysis of the sputtered Mo films. This analysis provided additional evidence for the development of texture via direct imaging of the film microstructure and diffraction from the top $\sim 500 \AA$ of the film. It is emphasized that the TEM specimens were always etched and ion milled from the back side, leaving the top $\sim 500 \AA$ of the film for analysis. The microstructure of films less than $40 \mathrm{~nm}$ thick consisted of polycrystalline, randomly oriented, fibrous grains with blunted growth fronts and a lateral grain size that slowly varied with film thickness. As the film thickness was increased above $80 \mathrm{~nm}$, grain renucleation was suppressed and columnar grains with faceted surfaces began to form. As shown in Fig. 5(a) most of the grains in the $200 \mathrm{~nm}$ films deposited at $34 \mathrm{~nm} / \mathrm{min}$ developed "elliptical" footprints. Cross section TEM and TED showed that these grains also had faceted surfaces and a common alignment of $\{110\}$ planes in the growth direction. On the other hand, Fig. 6(a) shows a more equiaxed in-plane grain structure for the films deposited at $67 \mathrm{~nm} / \mathrm{min}$. For these films, cross section TEM and TED also showed faceted surfaces and a predominant alignment of the $\{110\}$ planes in the growth direction. Furthermore, this alignment of the Mo $\{110\}$ planes in the growth direction became more pronounced as the film thickness increased (i.e., development of out-of-plane texture). Results from both plan view TED and TEM did not reveal any geometric or crystallographic alignment of the grains in the plane of growth.

The formation of an in-plane texture, a crystallographic and geometric alignment of grains in the plane of growth,

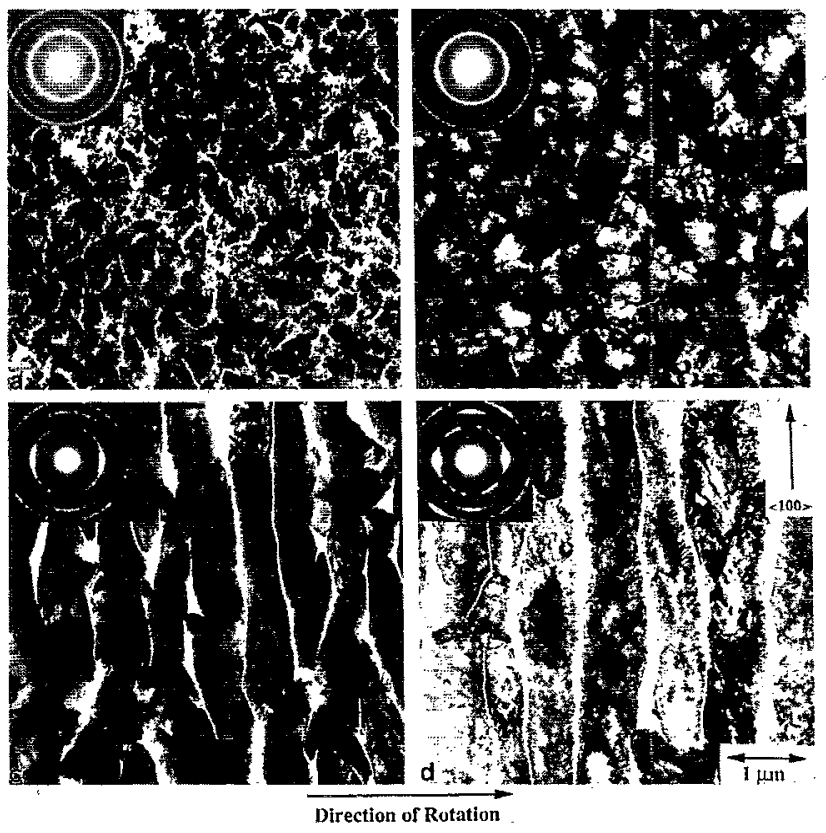

FIG. 5. Plan-view TEM micrographs and TED patterns for Mo films deposited at $34 \mathrm{~nm} / \mathrm{min}$ in the dynamic deposition geometry. Note: In all of the micrographs and diffraction patterns, the sample normal is parallel to the page normal. The TED patterns can be indexed in the following manner. Moving radially outward from the transmitted beam, the diffracted beams correspond to (110), (200), and (211) diffraction features: (a) $200 \mathrm{~nm}$ Mo films deposited at $34 \mathrm{~nm} / \mathrm{min}$, (b) $500 \mathrm{~nm}$ Mo film depösition at $34 \mathrm{~nm} / \mathrm{min}$, (c) $1 \mu \mathrm{m}$ Mo film deposited at $34 \mathrm{~nm} / \mathrm{min}$, (d) $2 \mu \mathrm{m}$ Mo film deposited at 34 $\mathrm{nm} / \mathrm{min}$. 
was noted in both plan view TFD patterns and TFM micrographs of thicker films [Figs. 5(b) $-5(\mathrm{~d}), 6(\mathrm{~b})-6$ (d)]. Plan view TED patterns in Figs. 5(b) and 6(b) for 500-nm-thick films exhibited an anisotropic distribution of diffraction maxima about the substrate normal and indicated the early stages of the development of an in-plane texture. This was also suggested in the plan view TEM micrographs [Figs. 5(b), 6(b)] where some geometric alignment of the grains in the plane of growth was observed. The development of an in-plane texture became more apparent as the film thickness was increased to $1 \mu \mathrm{m}$. Micrographs for the $1 \mu \mathrm{m}$ films [Figs. 5(c), 6(c)] clearly show faceted grains, as well as an alignment of the grains in the plane of growth. Films deposited at the lower rate [Fig. 5(c)] developed predominantly $\{110\}$ in-plane textures (a weak component of $\{111\}$ in-plane texture was also present in each film) and grains with elongated footprints. The $\{110\}$ textured grains had large aspect ratios with their major axes aligned along a $\mathrm{Mo}\langle 100\rangle$ direction. Films grown at the higher deposition rate [Fig. 6(c)] developed predominantly $\{111\}$ in-plane textures (a weak component of $\{110\}$ in-plane texture was also present in each film), as suggested by the TED patterns, and had grains with elongated triangular footprints. These pyramidal grains were aligned so that the elongated direction of each grain pointed along a Mo $\langle 112\rangle$ direction. In all of these films, the grains were elongated in a direction normal to the tangent plane. With increasing film thickness, the geometric alignment of the grains in the films increased, as did the average grain size [Fig. 5(d), 6(d)]. In general, the thicker Mo films developed microstructures which consisted of a loosely packed networks of columns with substantial intercolumnar void vol-

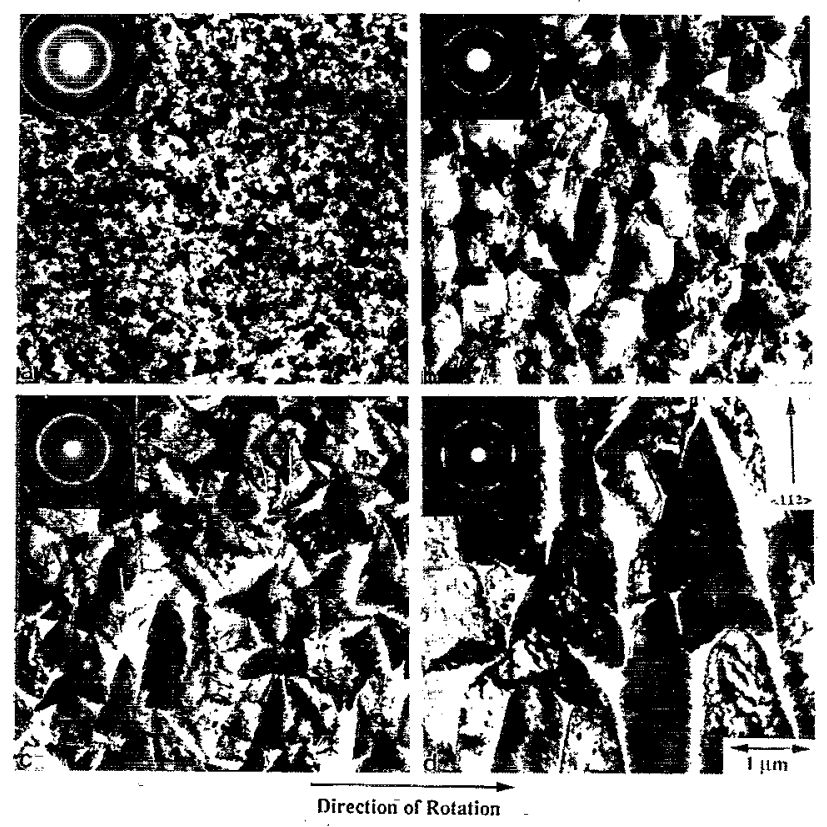

FIG. 6. Plan-view TEM micrographs and TED patterns for Mo films deposited at $67 \mathrm{~nm} / \mathrm{min}$ in the dynamic deposition geometry. See note in Fig. 5 caption: (a) $200 \mathrm{~nm}$ Mo film deposited at $67 \mathrm{~nm} / \mathrm{min}$, (b) $500 \mathrm{~nm}$ Mo film deposited at $67 \mathrm{~nm} / \mathrm{min}$, (c) $1 \mu \mathrm{m}$ Mo film deposited at $67 \mathrm{~nm} / \mathrm{min}$, (d) $2 \mu \mathrm{m}$ Mo film deposited at $67 \mathrm{~nm} / \mathrm{min}$.

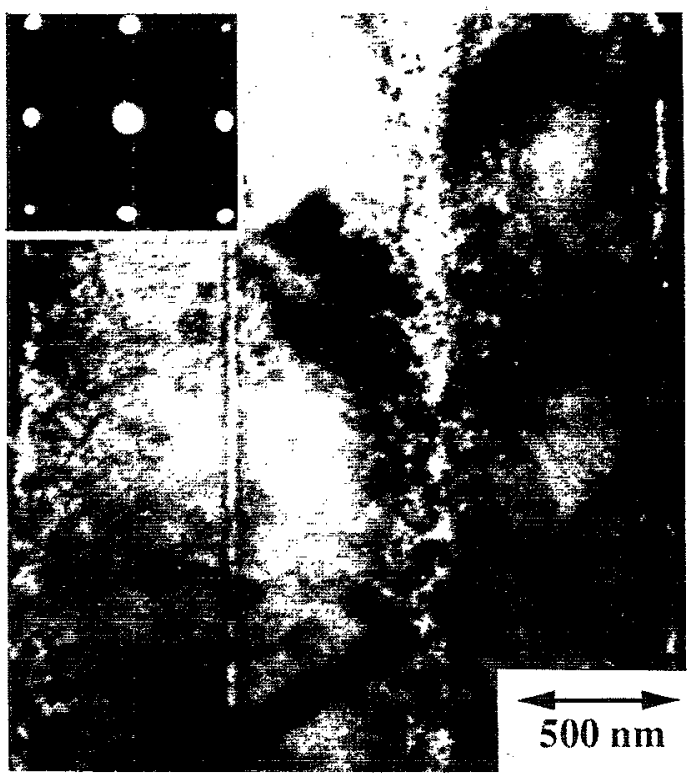

FIG. 7. Cross section TEM micrograph and TED pattern near the top of a 2 $\mu \mathrm{m}$ Mo film deposited at $34 \mathrm{~nm} / \mathrm{min}$. The TEM micrograph shows the columnar microstructure of the film. The TED pattern corresponds to a (200) zone axis pattern for a bcc material, and was obtained by placing an aperture about $\approx 8$ of the columns.

ume, $\approx 5 \%$ as measured by plan view TEM. Both plan view and cross section TED patterns for the $2 \mu \mathrm{m}$ Mo films (Fig. 7) suggested that the individual columns were single crystals that formed a highly textured film.

\section{B. Static deposition geometry}

Mo films were also sputter deposited onto stationary substrates at normal flux incidence, up to a thickness of 2 $\mu \mathrm{m}$. All of these films developed strong $\{110\}$ out-of-plane textures as determined by (110) pole figures [see Fig. 8(a)]. However, no significant in-plane texture was detected in any of these films. These observations were confirmed by plan view TED, while plan-view TEM micrographs showed elongated grains with faceted surfaces and no distinct in-plane alignment [see Fig. 8(b)]. Microdiffraction from individual grains showed an alignment of a Mo $\langle 100\rangle$ direction with the long axes of the elongated grains. TEM and $\mathrm{x}$-ray analyses were performed on two or more films of each thickness, grown at each set of deposition conditions. The results of these analyses were consistent with the results presented above.

\section{DISCUSSION}

Highly textured Mo films with both out-of-plane and inplane textures, and a zone 2 microstructure were grown at low substrate temperatures $\left(T<300{ }^{\circ} \mathrm{C}\right)$ by sputtering in a dynamic deposition geometry. The dynamic deposition geometry strongly influenced the development of in-plane texture in the Mo films. In all the films deposited onto moving substrates, a geometric and crystallographic alignment of the grains normal to the tangent plane was observed. Conversely, no significant in-plane texture was observed in any film de- 

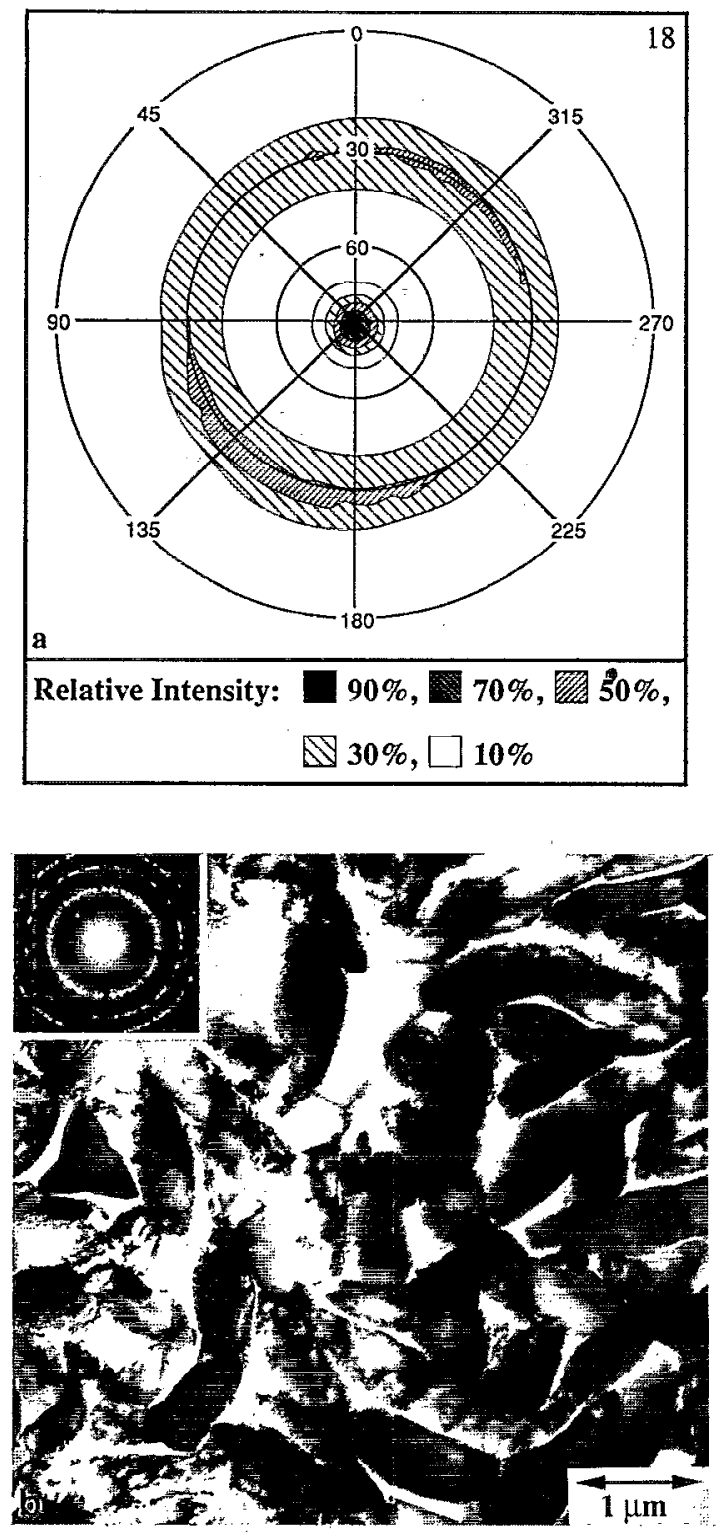

FIG. 8. (a) (110) pole figure for a $1 \mu \mathrm{m}$ Mo film deposited at $34 \mathrm{~nm} / \mathrm{min}$ in the static deposition geometry. See note in Fig. 3 caption. (b) Plan-view transmission electron micrograph and diffraction pattern for a $1 \mu \mathrm{m}$ Mo film deposited at $34 \mathrm{~nm} / \mathrm{min}$ in the static deposition geometry. See note in Fig. 5 caption.

posited in the static deposition geometry (films as thick as 2 $\mu \mathrm{m})$. Based on these observations it is likely that a "selfshadowing" mechanism ${ }^{37}$ is contributing to the development of the in-plane texture in the films grown in the dynamic deposition geometry. Microstructures similar to those seen in our films have been reported in many experimental ${ }^{4-6,9,19}$ and computer simulation studies ${ }^{9,11}$ where thin films were grown onto moving substrates or onto stationary substrates at oblique angles of the incident flux.

Further evidence demonstrating the effect of selfshadowing on the development of in-plane texture was provided by an additional experiment. In this experiment the role of the crystallographic orientation of the substrate on the development of in-plane texture was determined. Wafers were positioned on the rotatable platen with their major flats
( $(110\rangle$ directions) oriented at various angles to the direction of rotation. Films were deposited to a thickness of $1 \mu \mathrm{m}$. All of these films developed strong $\{110\}$ out-of-plane and inplane textures and an alignment of Mo $\langle 110\rangle$ directions normal to the tangent plane. In addition, the grains in each film had elongated footprints, faceted surfaces and an aligniment of their long axes (Mo $\langle 100\rangle$ directions) normal to the tangent plane. These results confirm that the dynamic sputtering geometry and the self-shadowing mechanism play an important role in the development of in-plane texture in the Mo films.

It is emphasized that although the self-shadowing mechanism can explain the alignment of the grains normal to the tangent plane in the Mo films, it cannot explain the alignment of specific crystallographic planes both in the direction of growth and in the plane of growth. ${ }^{9}$ We speculate that the development of this crystallographic anisotropy is also influenced by a number of kinetic and energetic factors which may include high strain energy that varies through the film thickness, ${ }^{23,24,38}$ strain enhanced diffusion, ${ }^{39}$ and anisotropic grain boundary, surface and interfacial energies. ${ }^{23-29}$ While a discussion of these factors and their influence on the development of in-plane texture is beyond the scope of this study, a brief discussion of these factors and their influence on the development of out-of-plane texture follows in the paragraphs below. It is noted that at least one other study has found that anisotropic surface and interfacial free energies can lead to the evolution of both out-of-plane and in-plane textures. ${ }^{25}$

The development of $\{110\}$ and $\{111\}$ textures in the sputtered Mo films appears to be a competitive process sensitive to deposition rate (power) and film thickness. Films deposited at $34 \mathrm{~nm} / \mathrm{min}(1.5 \mathrm{~kW})$ grew with predominantly $\{110\}$ textures for the entire range of thicknesses explored in this study. Similarly, films deposited at $67 \mathrm{~nm} / \mathrm{min}(3.9 \mathrm{~kW})$ grew with predominantly $\{110\}$ textures up to a film thickness of $\sim 0.5 \mu \mathrm{m}$. However, above a film thickness of $\sim 1 \mu \mathrm{m}$ the texture in these films transformed into a $\{111\}$ texture. Based on these data and on arguments considering the effect of various energetic factors on grain growth in thin films, ${ }^{23,24,26,27}$ we can speculate as to the mechanisms involved in the evolution of out-of-plane texture in these Mo films.

At small film thicknesses, where the surface to volume ratio in the film is high, minimization of surface free energy will dominate thin film growth. ${ }^{23,24,26,27}$ In this study, anisotropic substrate properties and their effect on thin film growth $^{26}$ can be ignored since the Mo films are grown on an amorphous layer of $\mathrm{SiO}_{2}$ which is assumed to be isotropic. For this case, it is reasonable to expect that $\{110\}$ oriented Mo grains would have a minimum surface free energy ${ }^{40,41}$ (in bcc materials $\{110\}$ planes have the highest planar packing density) and should have an energetic advantage for grain growth over grains with other crystallographic orientations. ${ }^{23,24,27}$ Hence, at small film thicknesses the Mo films should develop $\{110\}$ out-of-plane textures. $23,24,27$

At higher film thicknesses, where the surface to volume ratio in the film decreases, the total strain energy in the film will begin to contribute to the evolution of the 
microstructure. ${ }^{23,24}$ This effect has recently been addressed in theoretical studies concerning grain growth and the evolution of texture in fcc metal films. Results from these studies suggest that high stresses and differences in the elastic strain energy between grains of different crystallographic orientations can lead to the formation and propagation of various textures in a film. ${ }^{23,24}$ In our study, the transformation from $\{110\}$ to $\{111\}$ textures in films grown at the high rate (power) may also be related to high film stresses and differences in the elastic strain energy between $\{110\}$ and $\{111\}$ oriented grains. Previous studies have shown that Mo films sputtered at $10 \mathrm{mTorr}$ of $\mathrm{Ar}$ are under high tensile stresses, ${ }^{12,13,42,43}$ that the stress state in Mo films varies with film thickness ${ }^{38,44}$ and that Mo films with $\{111\}$ textures have a different stress state than Mo films with $\{110\}$ textures. ${ }^{42}$ As suggested above, these factors may cause the propagation of $\{111\}$ textures, as well as the continued growth of $\{110\}$ textures in films deposited at the high and low rates (powers), respectively. It is noted that differences between the stress states in the two sets of films can result from sputtering at different deposition powers. Current work is focused on addressing and quantifying the exact role of strain and strain energy in the development of out-of-plane textures.

The formation of a zone 2 microstructure accompanied the development of in-plane texture in the Mo films. At the initial stages of growth, the microstructure of the Mo films consisted of a network of small, randomly oriented grains. By a film thickness of $2 \mu \mathrm{m}$, the Mo films had developed highly oriented columnar microstructures with single crystal columns. These columns all bad faceted surfaces, characteristic grains shapes, and a common geometric and crystallographic alignment both in the direction of growth (out-ofplane texture) and in the plane of growth (in-plane texture). These microstructural features and the development of texture in the Mo films are characteristic of a zone 2 microstructure (dominated by surface diffusion and high grainboundary mobility). ${ }^{8-10}$ The development of a zone 2 microstructure in the Mo films is rather surprising since the films in this study were deposited at a low substrate temperature, $T<0.19 T_{m}$. At $0.19 T_{m}$, a zone 1 microstructure (characterized by continued grain renucleation) has been predicted due to limited adatom mobility. ${ }^{7,8,45}$ However, these data and results from a recent study of $\mathrm{Mo} / \mathrm{W}$ microlaminate composites grown under similar deposition conditions ${ }^{6} \mathrm{dem}-$ onstrate that a zone 2 microstructure can occur in Mo at temperatures below the "critical temperature" determined for the zone 1 to zone 2 transition $\left(T \sim 0.35 T_{m}\right)^{45,46}$ These results suggest that factors not previously addressed in the zone models are influencing the evolution of the thin film microstructures. These factors may be related to intrinsic film properties (e.g., varying stress states through the thickness of the films, ${ }^{38,44}$ impurities) or to extrinsic factors inherent to the deposition process (e.g., dynamic sputter geometry), and may also be affecting the development of texture in the Mo films.

\section{SUMMARY}

The use of TEM and TED complemented the use of conventional reflection $x$-ray pole figures in analyzing the texture of the Mo films. TEM and TED allowed direct imaging of the thin film microstructure and provided additional diffraction information about the planes normal to the growth direction. In addition, TED provided structural information from localized regions $\left(\sim 100 \mu \mathrm{m}^{2}\right)$ near the surface of the film (top $\sim 500 \AA$ ) , while $x$-ray pole figures provided structural information from larger regions $\left(\sim 2 \mathrm{~cm}^{2}\right)$ through the entire thickness of the film. 'The results from these techniques showed that the development of texture in local regions of the film corresponded to the development of texture in the entire film. In general, the development of out-of-plane textures was found to coincide with the formation of specific grains shapes and faceted surfaces, while the development of in-plane texture was found to coincide with the geometric alignment of grains in the plane of growth. Development of out-of-plane texture was influenced by the deposition rate. Development of the in-plane texture was not affected by changing the substrate orientation, but was affected by deposition geometry. Based on these data, it was proposed that the development of in-plane texture was influenced by a number of factors including a self-shadowing mechanism $9,11,19,37$ and anisotropic surface, grain boundary, and interfacial free energies. Current work is focused on determining the role of strain in the development of texture.

\section{ACKNOWLEDGMENTS}

This work is supported by the U.S.A.R.O. and ARPA, under Contract No. DAAL03-91-G-0235.

${ }^{1}$ S. P. Murarka, Metallization: Theory and Practice for VLSI and ULSI (Butterworth-Heinemann, Boston, 1993).

${ }^{2}$ D. P. Adams, M. Vill, J. Tao, J. C. Bilello, and S. M. Yalisove, J. Appl. Phys. 74, 1015 (1993).

${ }^{3}$ M. T. Kief and W. F. Egelhoff, Jr., J. Appl. Phys. 73, 6195 (1993).

${ }^{4}$ A. Kawamoto and F. Hikami, J. Appl. Phys. 69, 5151 (1991).

${ }^{5}$ M. R. Kim, S. Guruswamy, and K. E. Johnson, J. Appl. Phys. 74, 4643 (1993).

${ }^{6}$ S. Uchinami, F. Beppu, S. Ito, N. Tokubuch, K. Noda, Y. Notohara, and K. Kanai, IEEE Trans. Magn. MAG-23, 3408 (1987).

${ }^{7}$ B. A. Movchan and A. V. Demchishin, Phys. Met. Metallogr. 28, 83 (1969).

${ }^{8}$ J. A. Thornton, Ann. Rev. Mater. Sci. 7, 239 (1977).

${ }^{9}$ H. J. Leamy, G. H. Gilmer, and A. G. Dirks, Thin Solid Films 47, 219 (1977).

${ }^{10}$ C. R. M. Grovenor, H. T. G. Hentzell, and D. A. Smith, Acta Metall. 32, 773 (1984)

${ }^{11}$ D. Henderson, M. H. Brodsky, and P. Chaudhari, Appl Phys. Lett. 25, 641 (1974).

${ }^{12}$ T. J. Vink and J. B. A. D. van Zon, J. Vac. Sci. Technol. A 9, 124 (1991).

${ }^{13}$ H. Windischmann, Crit. Rev. Solid State Mater. Sci. 17, 547 (1992), and references cited within.

${ }^{14}$ J. G. W. van de Waterbeemd and G. W. van Oosterhout, Philips Res. Rep. 22, 375 (1967).

${ }^{15}$ A. N. Campbell, R. E. Mikawa, and D. B. Knorr, J. Electron. Mater. 22, 589 (1993).

${ }^{16}$ D. B. Knorr, D. P. Tracy, and K. P. Rodhell, Appl. Phys. Lett. 59, 3241 (1991).

${ }^{17} \mathrm{R}$. Penelle, in Texture of Materials, edited by G. Gottstein and K. Lucke (Springer, New York, 1978), pp. 129-153.

${ }^{18}$ P. R. Morris and J. W. Flowers, Texture Crystall. Solids 4, 129 (1981).

${ }^{19}$ D. O. Smith, M. S. Cohen, and G. P. Weiss, J. Appl. Phys. 31, 1755 (1960).

${ }^{20}$ F. C. Frank and J. H. van der Merwe, Proc. R. Soc. London A 198, 216 (1949).

${ }^{21}$ E. Bauer, Z. Krist 110, 372 (1958). 
${ }^{22}$ D. P. Adams, S. M. Yalisove, and D. J. Eaglesham, Appl. Phys. Lett. 63, 3571 (1994).

${ }^{23}$ J. E. Sanchez and E. Arzt, Scripta Metall. Mater. 27, 285 (1992).

${ }^{24}$ C. V. Thompson, Scripta Metall. Mater. 28, 167 (1993).

${ }^{25}$ J. A. Floro and C. V. Thompson, Acta Metall. Mater. 41, 1137 (1993).

${ }^{26}$ D. J. Srolovitz, J. Vac. Sci. Technol. A 4, 2925 (1986).

${ }^{37}$ C. V. Thompson, Ann. Rev. Mater. Sci. 20, 245 (1990).

${ }^{28}$ G. Abbruzzese and K. Lucke, Acta Metall. Mater. 34, 905 (1986).

${ }^{29} \mathrm{H}$. Eichelkraut, G. Abbruzzese, and K. Lucke, Acta Metall. Mater. 36, 55 (1988).

${ }^{30} \mathrm{D}$. D. Dobrev, in Texture of Materials, edited by G. Gottstein and $\mathrm{K}$. Lucke (Springer, New York, 1978), pp. 171-179.

${ }^{31}$ I. M. Fisher and D. A. Smith, Textures and Microstructures 13, 91 (1991).

${ }^{32}$ A. A. Macdowell, NSLS Newsletter, March, pp. 4-5 (1994).

${ }^{33}$ J. M. Harris, E. Lugujjo, S. U. Campisano, M.-A. Nicolet, and R. J. Shima, J. Vac. Sci. Technol. 12, 524 (1975).

${ }^{34}$ L. G. Schultz, J. Appl. Phys. 20, 1030 (1949).

${ }^{35}$ Correction term used in the pole figure analysis software provided by Rigaku.
${ }^{36}$ The convention of quantifying texture with a "times random" scale can be seen in numerous references, including C. S. Barrett and T. B. Massalski, Structure of Metals (McGraw-Hill, New York, 1966), pp. 541-567.

${ }^{37} \mathrm{H}$. Konig and G. Helwig, Optik 6, 111 (1950).

${ }^{38}$ S. G. Malhotra, Z. Rek, M. Vill, O. P. Karpenko, S. M. Yalisove, and J. C. Billelo, Material Research Society Symposium Proceedings (Materials Research Society, Pittsburgh, 1994), Vol. 317, p. 473.

${ }^{39}$ D. J. Srolovitz, Acta Metall. Mater. 37, 621 (1989).

${ }^{40}$ W. Kossel, Nachr. Ges. Wiss. Gottingen, 135 (1927).

${ }^{41}$ S. M. Foiles, Phys. Rev. B 48, 4287 (1993).

${ }^{42}$ M. Zaouali, J. L. Lebrun, and Z. Gergaud, Surf. Coat. Technol. 50, 5 (1991).

${ }^{43}$ D. W. Hoffman and J. A. Thornton, J. Vac. Sci. Technol. 20, 355 (1982).

${ }^{44}$ T. J. Vink, M. A. J. Somers, J. L. C. Daams; and A. G. Dirks, J. Appl. Phys. 70, 4301 (1991).

${ }^{45}$ A. Mazor, D. J. Srolovitz, P. S. Hagen, and B. G. Bukiet, Phys. Rev. Lett. 60, 424 (1988).

${ }^{46}$ M. A. Sherman, R. F. Bunshaw, and H. A. Beale, J. Vac. Sci. Technol. 12, 697 (1975). 